\title{
Survey of the konzo prevalence of village people and their nutrition in Kwilu District, Bandundu Province, DRC
}

\author{
Jean Pierre Banea ${ }^{1}$, J. Howard Bradbury ${ }^{2 \star}$, Damien Nahimana ${ }^{1}$, Ian C. Denton ${ }^{2}, \mathrm{~N}$. \\ Mashukano ${ }^{1}$ and N'landa Kuwa ${ }^{1}$ \\ ${ }^{1}$ Programme National de Nutrition (PRONANUT), Kinshasa, Democratic Republic of Congo (DRC). \\ ${ }^{2}$ EEG, Research School of Biology, Australian National University, Canberra, ACT 0200, Australia.
}

Received 4 September, 2014; Accepted 7 January, 2015

\begin{abstract}
Konzo is a sudden spastic paraparesis that causes permanent paralysis of the legs and occurs mainly in children and young women. Konzo results from high cyanogen intake and malnutrition caused by a monotonous diet of bitter cassava. The known incidence of konzo in DRC up to 2009 is 3469 cases, but an estimate in 2002 was 100,000 cases. To help resolve this question a konzo survey was made in three health zones in Kwilu District, Bandundu Province, Democratic Republic of Congo (DRC), and the nutrition of those with konzo recorded. Thirty villages (population 22793) in Kwilu District were surveyed for konzo cases, and food consumption scores and mid upper arm circumferences obtained. There were 172 konzo cases with village konzo prevalences of $0.1-17 \%$. The mean konzo prevalence in Masimanimba and Kingandu health zones was much less than in Payikongila health zone, probably because of the higher rate of malnutrition in Payikongila. Since 2009, konzo incidence has increased greatly in Kwilu District and also in 13 villages in nearby Kwango District, where incidence of new konzo cases has been prevented by use of the wetting method. Averaging the data over 495 konzo cases, $48 \%$ occurred from 2009 onwards and $52 \%$ occurred in the $20+$ years before 2009. The very large increase of konzo incidence since 2009 is a public health problem in Bandundu Province, that could be solved by training women to use the wetting method, which removes cyanogens from cassava flour. The wetting method is more direct, effective and cheaper in preventing konzo than broad based interventions.
\end{abstract}

Key words: Konzo survey, cassava, cyanide, nutrition, sulfur amino acids, food consumption score, mid upper arm circumference.

\section{INTRODUCTION}

Cassava contains cyanogens (linamarin and a small amount of lotaustralin) that on consumption liberate cyanide in the body, which can lead to konzo, an irreversible spastic paraparesis of the legs that occurs suddenly amongst very

${ }^{*}$ Corresponding author. E-mail: howard.bradbury@anu.edu.au.

Author(s) agree that this article remain permanently open access under the terms of the Creative Commons Attribution License 4.0 International License 
poor village people who live on a monotonous diet of bitter cassava (Cliff et al., 1985; Howlett et al., 1990; Nzwalo and Cliff, 2011). Konzo is an upper motor neuron disease that causes permanent paralysis of the legs and affects mainly children and young women after childbirth. Many of these people suffer from malnutrition with low protein intake, in particular a shortfall of the essential sulfur amino acids methionine and cysteine/cystine that are needed for detoxification of cyanide (CN) to thiocyanate (SCN) in the body (Cliff et al., 1985). Konzo occurs in the Democratic Republic of Congo (DRC), Mozambique, Tanzania, Cameroon, Central African Republic and Angola (Bradbury et al., 2011; Allen, 2010) and because of the very large per capita consumption of cassava in Congo (Nhassico et al., 2008) konzo probably occurs there as well. The total number of konzo cases reported up to 2009 is 6788 (Nzwalo and Cliff, 2011), with 3469 cases in DRC, but this is very much less than the true number, because konzo occurs in isolated areas and during crises such as war and drought. An estimate of 100,000 konzo cases in DRC was made in 2002 (Diasolua Ngudi, 2005). In 2010 Action Against Hunger (ACF) in Kwango District, Bandundu Province, DRC, located 2218 konzo cases (Kasonga and Calo, 2011; Delhourne et al., 2012). Konzo occurs in at least four provinces, Bandundu, Kasai Oriental, Kasai Occidental and South Kivu (Chabwine et al., 2011) (Figure 1), but there has been no country wide survey of konzo in the DRC.

Konzo has been prevented in 13 villages in the DRC with a population of nearly 10000 people by use of the wetting method by village women to remove cyanogens from cassava flour (Banea et al., 2012, 2013, 2014a). The wetting method consists of adding water to cassava flour, spreading the wet flour in a thin layer on a mat for 2 $\mathrm{h}$ in the sun or $5 \mathrm{~h}$ in the shade to allow the escape of hydrogen cyanide gas produced by breakdown of linamarin by the enzyme linamarase (Bradbury, 2006; Cumbana et al., 2007; Bradbury and Denton, 2010). The damp flour is then cooked in the traditional way to make a thick porridge called fufu. The women readily accepted the wetting method and still continued to use it more than a year after the intervention ceased and the method has spread by word of mouth to other villages (Banea et al., 2014b). Furthermore, a correlation has been found between the monthly percentage incidence of konzo and the monthly cyanide intake as measured by the urinary thiocyanate content of children (Banea et al., 2014a). It is therefore likely that konzo results from high cyanide intake from bitter cassava, coupled with a low intake of sulfur amino acids.

It is important to have a good estimate of the total number of people with konzo in DRC and other countries, so that the prevention methods that we have developed can be systematically applied towards the complete prevention of this disease. In this paper we report the konzo prevalence and nutrition of konzo cases in 30 villages in three health zones in Kwilu District, Bandundu Province.

\section{MATERIALS AND METHODS}

\section{Study area}

In order to discover the most affected konzo areas in Kwilu District, discussions were held with Kwilu District health authorities in Kikwit in July 2012. Four health zones were identified as most affected Masimanimba, Kingandu, Payikongila and Djuma, but Djuma health zone was excluded for logistical reasons (Figure 1). Thirty four villages were identified as most affected and konzo cases were found in thirty villages.

\section{Food and diseases of the people}

The most important food crops are cassava, maize, peanuts, squash and cowpeas. Cassava is the staple food eaten as fufu, mainly with cassava leaves and vegetables. There is some small livestock, poultry, small scale fishing and fish farming for sale. The dry season is from mid-May to mid-August and there is another short dry season in February-March. There are two lean periods in August to November and in March, when household food security is critical and the number of meals is reduced to one meal per day. The most common diseases are malaria, acute respiratory infection, diarrhea, malnutrition and trypanosomiasis.

\section{Health zone visits and survey methods}

Discussion were conducted with the health authorities in each of the three health zones and supervisors were identified in each zone. Four supervisors were given training in Kikwit City by the konzo team of Programme National de Nutrition (PRONANUT). Each trained supervisor was responsible for collecting data on konzo cases in the health areas of his health zone. In each health zone the most affected villages were identified first. A census was taken of each affected village and suspected cases of konzo or those with gait difficulties were identified by the community health workers, who are trained to recognise common diseases including konzo and to refer the case to a health centre. Konzo cases were examined by doctors from PRONANUT following a standardised protocol (World Health Organisation, 1996) as follows: (1) a visible spastic walk or run, (2) an abrupt history of the onset of the disease in less than one week in a person in good health, with no futher progression of the disease, (3) a bilateral exaggeration of knee jerks and/or Achilles tendon (ankle clonus). The month and year were recorded when konzo occurred. Five surveyors were trained to administer the food household consumption questionnaire for each family with a case of konzo.

\section{Food consumption score (FCS) in konzo household}

The food consumption data of 155 households with konzo (some had multiple cases of konzo) were surveyed in the three health zones and this was used to calculate the World Food program food consumption score (FCS) using the equation:

FCS $=a_{\text {staple }} x_{\text {staple }}+a_{\text {pulse }} x_{\text {pulse }}+a_{\text {veg }} x_{\text {veg }}+a_{\text {fruit }} x_{\text {fruit }}+a_{\text {animal }} x_{\text {animal }}$ $+a_{\text {sugar }} x_{\text {sugar }}+a_{\text {oil }} x_{\text {oil }}$,

Where $x_{i}=$ number of days for which each food group was consumed during the past seven days, $a_{i}=$ weight of each food 


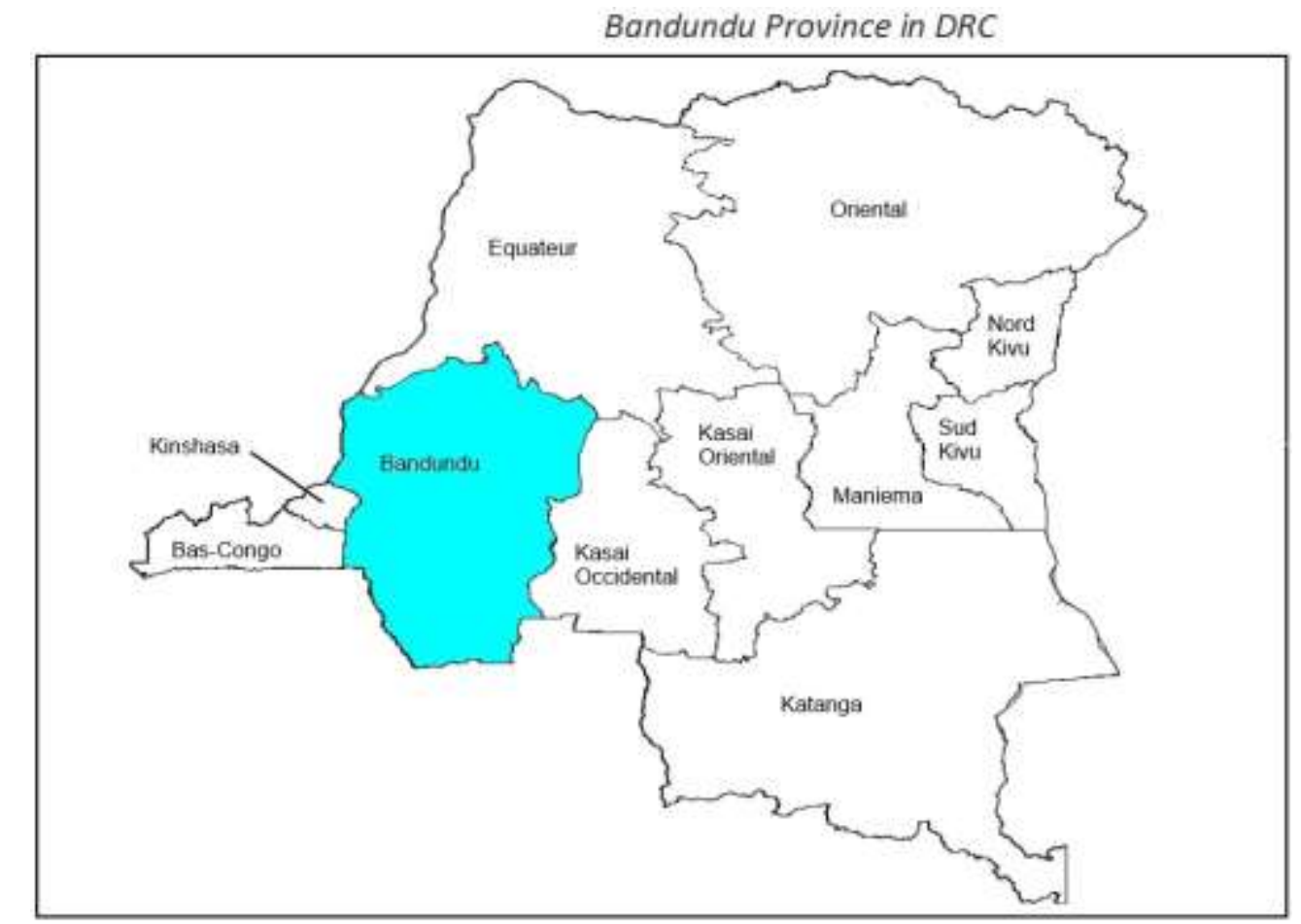

A

Districts of Bandundu province

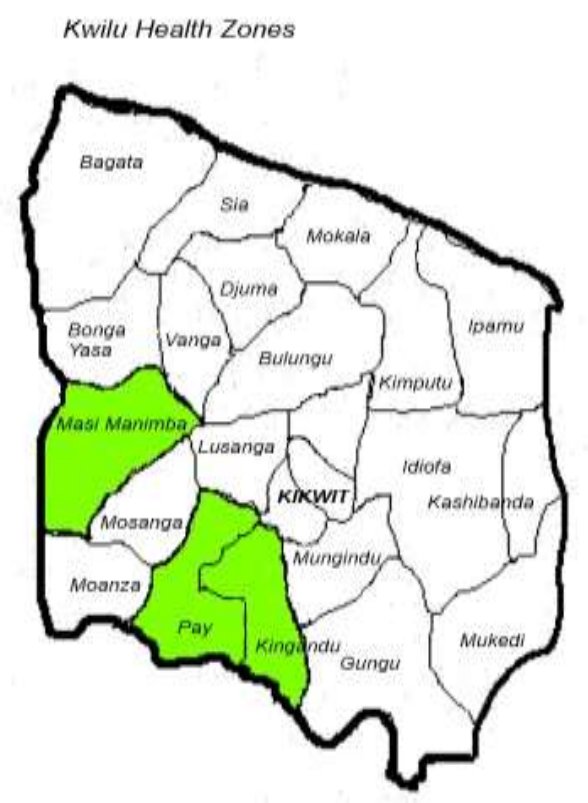

B

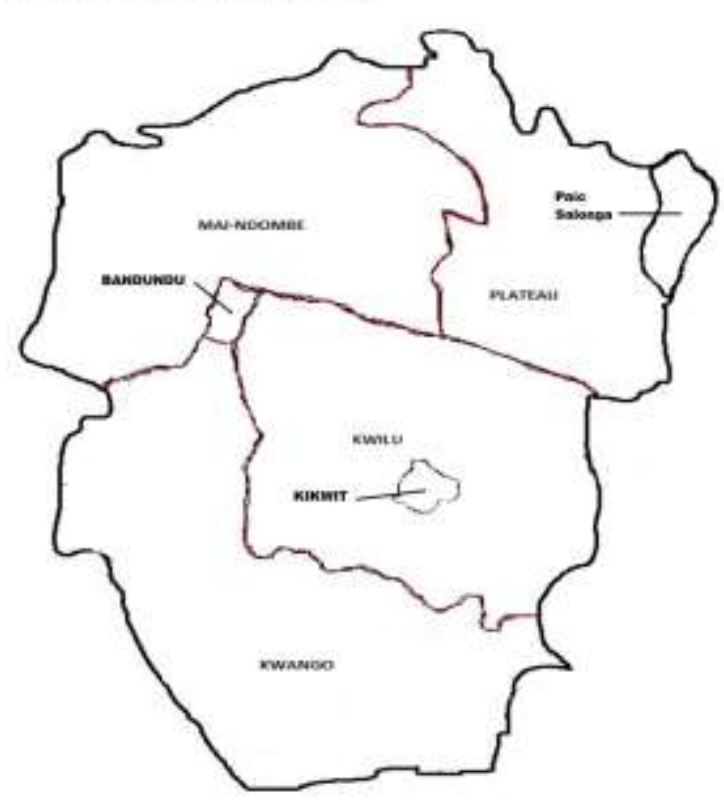

C

Figure 1. A.The provinces of DRC showing Bandundu, Kasai Occidental, Kasai Oriental and South Kivu where konzo is present; B. Health zones of Kwilu District with the survey ones marked; C. Districts of Bandundu Province.

group as follows: staple (cassava) 2, pulses (beans, peas, groundnuts) 3 , vegetables and leaves 1 , fruit 1 , meat and fish 4 , milk 4 , sugar 0.5 , oils, fats and butter 0.5 . The thresholds used were: 0-23.9 for poor food consumption, 24.0-37.9 for borderline food consumption, and >=38 for acceptable food consumption (Interagency Work. Rep. WFP-FAO 2008).

\section{Mid upper arm circumference (MUAC) and nutritional status}

The mid upper arm circumference was used in order to identify high-risk malnourished (> 18 years old) konzo patients (Unicef 2012; Projet Sphere). A MUAC of $<210 \mathrm{~mm}$ indicated a person with malnutrition. There were 64 konzo patients measured in 
Table 1. Percentage konzo prevalence in descending order for thirty villages in Kwilu District.

\begin{tabular}{|c|c|c|c|}
\hline Village & Population & Number of konzo cases & $\%$ Konzo \\
\hline Kongila Ndola ${ }^{a}$ & 106 & 18 & 17.0 \\
\hline Kongila Kianfu ${ }^{a}$ & 495 & 38 & 7.7 \\
\hline Lubamba $^{\mathrm{a}}$ & 341 & 9 & 2.6 \\
\hline Kinzefa $^{\mathrm{a}}$ & 420 & 8 & 1.9 \\
\hline Kabanga $^{\mathrm{b}}$ & 564 & 6 & 1.1 \\
\hline Kiwawa Kapa ${ }^{\mathrm{C}}$ & 1453 & 12 & 0.83 \\
\hline Mulasi $^{\mathrm{C}}$ & 248 & 2 & 0.81 \\
\hline Kizefo $^{c}$ & 1153 & 9 & 0.78 \\
\hline Kiwawa Pont $^{\mathrm{C}}$ & 1805 & 13 & 0.72 \\
\hline Mvudib $^{b}$ & 564 & 4 & 0.71 \\
\hline Makanga $^{\mathrm{C}}$ & 1047 & 7 & 0.67 \\
\hline Mashini $^{\mathrm{b}}$ & 734 & 4 & 0.54 \\
\hline Kipongi $^{\mathrm{C}}$ & 1104 & 6 & 0.54 \\
\hline Kikonga $^{c}$ & 751 & 4 & 0.53 \\
\hline Kimeso $^{\circ}$ & 231 & 1 & 0.43 \\
\hline Yoshic $^{\mathrm{C}}$ & 467 & 2 & 0.43 \\
\hline Cite Masi ${ }^{\mathrm{C}}$ & 734 & 3 & 0.41 \\
\hline Sakanib & 734 & 3 & 0.41 \\
\hline Mbeko $^{\mathrm{C}}$ & 1030 & 4 & 0.39 \\
\hline Lunza $^{c}$ & 805 & 3 & 0.37 \\
\hline Bibamba $^{\mathrm{c}}$ & 549 & 2 & 0.36 \\
\hline Kifunga Centre ${ }^{c}$ & 2420 & 6 & 0.25 \\
\hline Kikongo $^{c}$ & 400 & 1 & 0.25 \\
\hline Kilombo $\mathrm{M}^{\mathrm{c}}$ & 405 & 1 & 0.25 \\
\hline Kiwamba $^{c}$ & 534 & 1 & 0.19 \\
\hline Kikiama $^{\mathrm{C}}$ & 564 & 1 & 0.18 \\
\hline Kimpembe $^{c}$ & 564 & 1 & 0.18 \\
\hline $\mathrm{Kiko}^{\mathrm{C}}$ & 734 & 1 & 0.14 \\
\hline Kinzenga $Q 3^{\mathrm{C}}$ & 950 & 1 & 0.11 \\
\hline Mudigongo $^{c}$ & 887 & 1 & 0.11 \\
\hline Total & 22793 & 172 & \\
\hline
\end{tabular}

${ }^{a}$ Payikongila health zone; ${ }^{b}$ Kingandu health zone; ${ }^{c}$ Masimanimba health zone

Masimanimba, 13 in Kingandu and 46 in Payikongila.

\section{Ethics statement}

The Ministry of Public Health Ethics Committee in DRC approved the survey protocol, which was also approved by Kwilu district health authorities and health zone health authorities. The chiefs of the villages accepted the census and medical examination of their people for konzo and distribution of a questionnaire on food consumption.

\section{RESULTS}

Thirty villages were identified in Masimanimba, Kingandu and Payikongila health zones to be surveyed, 22 in Masimanimba, four in Kingandu and four in Payikongila health zones. In a population of 22793 people there were 266 people with walking difficulties of whom 172 had konzo, giving a mean konzo prevalence of $0.75 \%$ (Table 1). The four villages in Payikongila health zone had the highest konzo prevalences ranging from $17 \%$ down to $1.9 \%$ with $42 \%$ of the total konzo cases. The main group of villages in Kingandu and Masimanimba health zones had konzo prevalences ranging from $1.1 \%$ down to $0.11 \%$ (with 9 villages recording only one konzo case) and accounting for $58 \%$ of the total number of konzo cases. Overall $53 \%$ were female and $47 \%$ male. Of the women who contracted konzo, $12 \%$ were nursing a baby at the time of the konzo attack. The age at onset was 2-4 years, 9\%; 5-14 years, 53\%; 15-44 years, 34\%; 45-55 years, $4 \%$. There was an abrupt onset in less than one day in $83 \%$ of cases and the remainder over 2-7 days. 
Table 2. Comparison of $\%$ konzo prevalence, $\%$ malnutrition ${ }^{\mathrm{a}}$ and $\%$ nutrition (poor, borderline, acceptable) ${ }^{\mathrm{b}}$ of people in three Kwilu health zones.

\begin{tabular}{|c|c|c|c|c|c|}
\hline \multirow{2}{*}{ Health zone } & \multirow{2}{*}{$\%$ Konzo prevalence } & \multirow{2}{*}{$\begin{array}{c}\% \\
\text { Malnutrition }^{\mathrm{a}}\end{array}$} & \multicolumn{3}{|c|}{ Nutrition (\%) based on food consumption score } \\
\hline & & & Poor & borderline & acceptable \\
\hline Masimanimba & 0.44 & 20 & 11 & 28 & 61 \\
\hline Kingandu & 0.66 & 8 & 18 & 6 & 76 \\
\hline Payikongila & 5.4 & 50 & 22 & 38 & 40 \\
\hline
\end{tabular}

${ }^{a}$ Based on mid upper arm circumference (MUAC) measurement of adult konzo patients (Unicef, 2012; Projet Sphere) ${ }^{\text {b }}$ Based on food consumption score (FCS) of konzo families, see methods (Interagency Work. Rep., WHO-FAO, 2008).

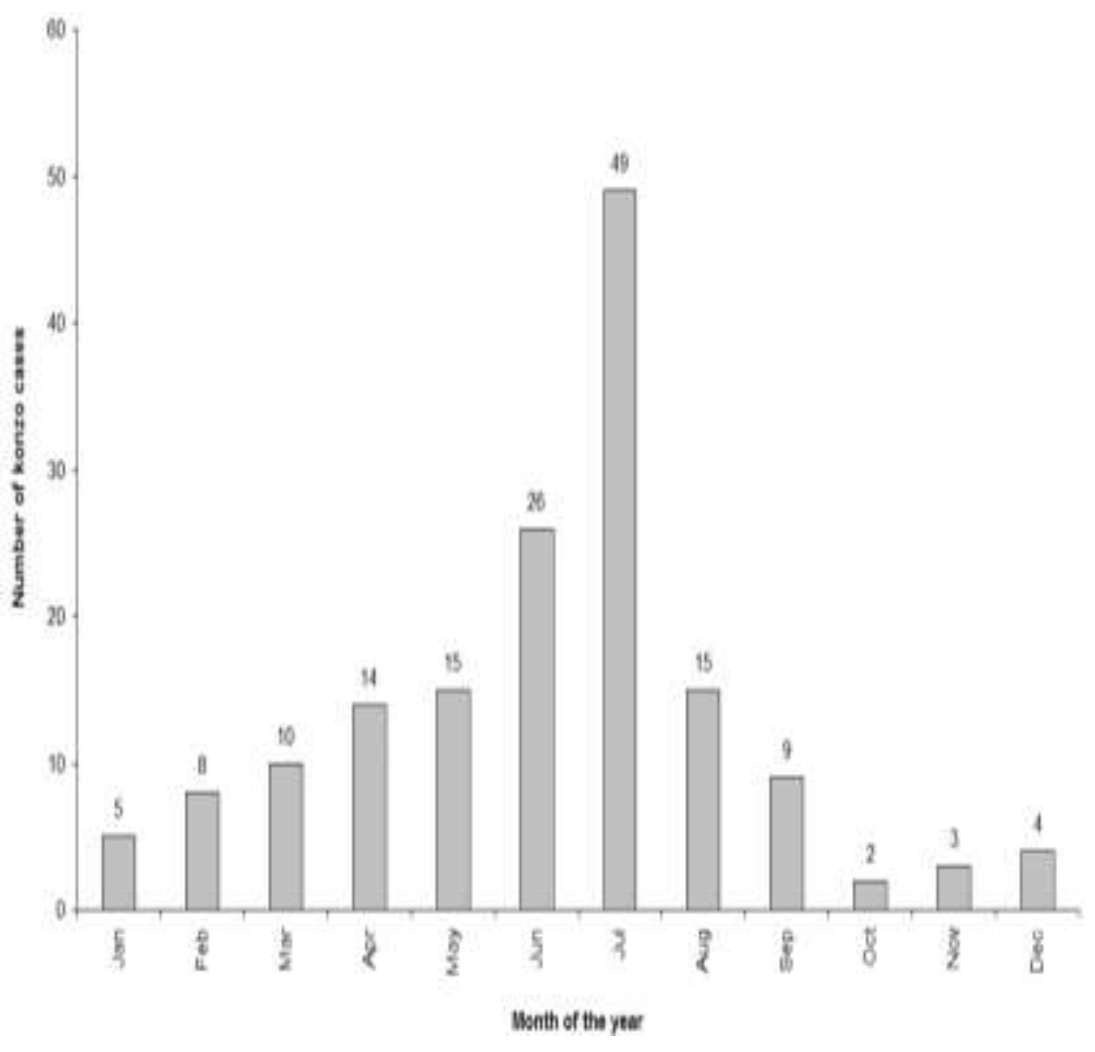

Figure 2. Monthly distribution of onset of konzo cases.

Bilateral exaggerated knee jerks were observed in $96 \%$ of cases. Speech disorders occurred in $22 \%$ of konzo cases, $17 \%$ had blurred vision and $2 \%$ goitre. It was found that $7 \%$ of people with konzo were unable to walk, $25 \%$ needed one or two sticks and $68 \%$ walked unaided but with a limp. These numbers have been combined with those from six other konzo studies in DRC and Tanzania (Banea et al., 2014a) and the results (mean +/- SD) are $8+/-5$ severe, unable to walk; $26+/-13$ moderate, needing one or two sticks; $66+/-12$ mild, no sticks needed.

Table 2 shows the mean konzo prevalence in each health zone, \% malnutrition among konzo cases measured by MUAC and the nutrition measured by a food consumption survey of the konzo families. The monthly occurrence of konzo cases is shown in Figure 2 and the years in which they occurred in Figure 3 . The peeled cassava roots are soaked (retted) in a pond or a stream or at home for 2-3 days, but only for 1-2 days during the dry season. About one third of the konzo households surveyed had difficulty to ensure proper soaking, due to theft during soaking in $87 \%$ of cases or lack of water in $13 \%$ of cases. One quarter of households had consumed only one meal the day before the survey in July. Survival strategies used during periods of food shortage (August to November and in March) were to fall back on food gathering, use of less preferred foods and also to harvest crops early. Nearly all households (93\%) with cases of konzo had houses made of straw and only $12 \%$ had 


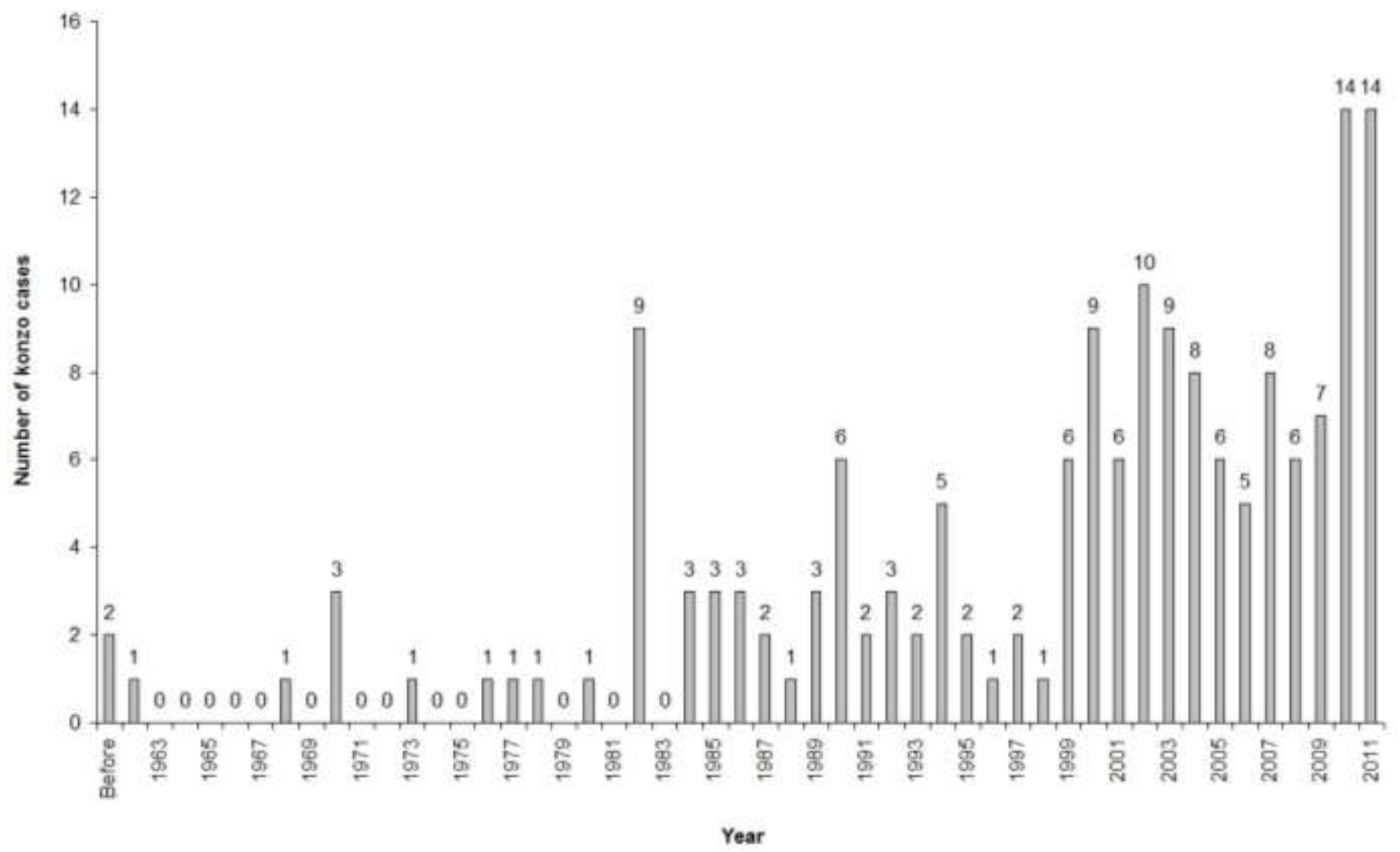

Figure 3. Annual distribution of onset of konzo cases.

access to a source of safe drinking water.

\section{DISCUSSION}

The data in Table 1 show that konzo prevalence is very high in four villages of Payikongila health zone with $42 \%$ of total konzo cases and much less in the 26 villages of Kingandu and Masimanimba health zones with $58 \%$ of total konzo cases. The high konzo prevalence in Payikongila health zone is probably due to the much poorer nutrition and higher degree of malnutrition of konzo cases in Payikongila compared with konzo patients from the other health zones (Table 2). Unfortunately, we do not have the urinary thiocyanate content of the school children, which would have allowed comparison between the cyanide intake of children from each health zone.

In Figure 2, the monthly incidence of konzo throughout the year shows a strong maximum incidence in July, the peak cassava harvesting season in the dry season, which agrees with previous work (Banea et al., 2012, 2013). The survey of konzo families showed that short soaking for 1-2 days instead of 3-4 days (Banea et al., 1992) was common especially in the dry season, which together with a peak in consumption of cassava, caused a peak in both cyanogen intake and konzo. The yearly incidence of konzo (Figure 3) shows that konzo cases have occurred every year since 1984, with much larger annual numbers since 1999, particularly in 2010 and 2011. This confirms the very concerning results found in 13 villages in Popokabaka and Boko health zones in nearby Kwango district, where konzo incidence has greatly increased since 2009 in this area of Bandundu Province (Banea et al., 2012, 2013, 2014a). By combining the data from this survey and the four interventions, it was found that $48 \%$ of the konzo incidences were in the three years from 2009 onwards and $52 \%$ in the preceding $20+$ years.

By the successful use of the wetting method by village women to remove cyanogens from cassava flour we have prevented konzo in 13 villages with 9191 people (Banea et al., 2012, 2013, 2014a). Furthermore, we have shown that there is a significant correlation between month by month percentage konzo incidence and monthly cyanide intake, as measured by the percentage of children with high urinary thiocyanate content (Banea et al., 2014a). It is therefore likely that konzo arises from high cyanide intake and malnutrition, specifically a shortfall of sulfur amino acids, also being a factor (Nzwalo and Cliff, 2011). We have prevented konzo by decreasing cyanide intake, but the results in Table 2 suggest that malnutrition may 
be an important factor. The importance of malnutrition was evident in three unrelated konzo epidemics in which people of the same ethnic group as those who had high konzo prevalence, but living only about $5 \mathrm{~km}$ away had virtually zero konzo prevalence. Those who were protected from konzo in the Mozambique konzo epidemic lived near the sea and consumed fish (Ministry of Health, 1984), as did those in Tanzania who lived near Lake Victoria (Howlett et al., 1992) and those protected in DRC lived in the forest and ate animals from the forest (Banea Mayambu, 1993). Thus, improvement of the diet particularly by inclusion of animal protein is probably a means of preventing konzo. This is part of the cross-sectoral approach used by Action Against Hunger (ACF) (Kasongo and Calo, 2011). The intervention of ACF has reduced konzo incidence by $84 \%$ between 2010 and 2011 (Delhourne et al., 2012). The reduction of cyanide intake by educating the women about the cause of konzo and how to use the wetting method to remove cyanogens, is direct, effective and less expensive than the crosssectoral approach which involves improvement of the diet and other factors. Ideally, reduction of cyanide intake and reduction of malnutrition should be used together (Cardoso et al., 2005).

\section{Conclusion}

In three health zones of Kwilu District there were 172 cases of konzo in 30 villages. The villages of Payikongila health zone had much higher konzo prevalences and the konzo cases much poorer nutrition, than in the villages of Masimanimba and Kingandu health zones. Since 2009 there has been a large increase of yearly konzo incidence in four interventions to prevent konzo using the wetting method in nearby Kwango District and also in this survey in Kwilu District. Using the data from the four interventions and this survey it was found that $48 \%$ of konzo cases occurred from 2009 onwards and $52 \%$ of cases in 20+ years preceding 2009. The use of the wetting method to reduce cyanogen intake has prevented konzo in 13 villages costing an average $\$ 27$ per person and is more effective in preventing konzo and cheaper than broad based interventions.

\section{Conflict of interests}

The authors did not declare any conflict of interest.

\section{ACKNOWLEDGMENTS}

We thank the Kwilu district health authorities and the health zone authorities for Masimanimba, Kingandu and Payikongila health zones. We also thank the village chiefs and all the people involved in this konzo and nutrition survey.

\section{REFERENCES}

Allen TJ (2010). Konzo in Angola. CCDN News No 16, 3-4.

Banea JP, Bradbury JH, Mandombi C, Nahimana D, Denton IC, Foster MP, Kuwa N, Tshala Katumbay D (2014a). Prevention of konzo in the DRC using the wetting method and correlation between konzo incidence and percentage of children with high urinary thiocyanate level. Afr. J. Food Sci. 8:297-304.

Banea JP, Bradbury JH, Mandombi C, Nahimana D, Denton IC, Kuwa N, Tshala Katumbay D (2013). Control of konzo by detoxification of cassava flour in three villages in the Democratic Republic of Congo. Food Chem. Toxicol. 60:506-513.

Banea JP, Bradbury JH, Mandombi C, Nahimana D, Denton IC, Kuwa N, Tshala Katumbay D (2014b). Effectiveness of wetting method for control of konzo and reduction of cyanide poisoning by removal of cyanogens from cassava flour. Food Nutr. Bull. 35:28-32.

Banea JP, Nahimana D, Mandombi C, Bradbury JH, Denton IC, Kuwa N (2012). Control of konzo in DRC using the wetting method on cassava flour. Food Chem. Toxicol. 50:1517-23.

Banea JP, Poulter NH, Rosling H (1992). Shortcuts in cassava processing and risk of dietary cyanide exposure in Zaire. Food Nutr. Bull. 14:137-143.

Banea Mayambu JP (1993). Cassava processing, dietary cyanide exposure and konzo in Zaire. Masters Thesis. Uppsala University, Uppsala, Sweden, p. 55.

Bradbury JH (2006). Simple wetting method to reduce cyanogen content of cassava flour. J. Food Comp. Anal. 19:388-93.

Bradbury JH, Cliff J, Denton IC (2011). Uptake of wetting method in Africa to reduce cyanide poisoning and konzo from cassava. Food Chem. Toxicol. 49:539-542.

Bradbury JH, Denton IC (2010). Rapid wetting method to reduce cyanogen content of cassava flour. Food Chem. 121:591-94.

Cardoso AP, Mirione E, Ernesto M, Massaza F, Cliff J, Haque MR, Bradbury $\mathrm{JH}$ (2005). Processing of cassava roots to remove cyanogens. J. Food Comp. Anal. 18:451-460.

Chabwine JN, Masheka C, Balol'ebwami Z, Maheshe B, Balegamire S, Rutega B, wa Lola M, Mutendela K, Bonnet MJ, Shangalume O, Balegasmire JM, Nemery B (2011). Appearance of konzo in South Kivu, a wartorn area in the Democratic Republic of Congo. Food Chem. Toxicol. 40:644-649.

Cliff J, Martensson J, Lundquist P, Rosling H, Sorbo B (1985). Association of high cyanide and low sulphur intake in cassava induced spastic paraparesis. Lancet 11:1211-13.

Cumbana A, Mirione E, Cliff J, Bradbury JH (2007). Reduction of cyanide content of cassava flour in Mozambique by the wetting method. Food Chem. 101:894-97.

Delhourne MM, Mayans J, Calo M, Guyot-Bender C (2012). Impact of cross-sectoral approach to addressing konzo in DRC. Field Exch. 44:50-54.

Diasolua Ngudi D (2005). Konzo and cassava toxicity: a study of associated nutritional factors in the Popokabaka District, DRC. Ph D Thesis, Universiteit Gent, Belgium.

Howlett WP, Brubaker G, Mlingi N, Rosling H (1992). A geographical cluster of konzo in Tanzania. J. Trop. Geogr. Neurol. 2:102-108.

Howlett WP, Brubaker GR, Mlingi N, Rosling H (1990) Konzo, an epidemic upper motor neuron disease studied in Tanzania. Brain 113:223-35.

Interagency Workshop Report WFP-FAO (2008). Measures of Food Consumption-Harmonizing Methodologies. April 2008, Rome. Italy.

Kasonga E, Calo M (2011). A cross-sectoral approach to addressing konzo in DRC. Field Exch. No 41, 3-5.

Ministry of Health Mozambique (1984). Mantakassa: an epidemic of spastic paraparesis associated with chronic cyanide intoxication in a cassava staple area in Mozambique. 1. Epidemiology and clinical laboratory findings in patients. Bull. WHO 62:477-484.

Nhassico D, Muquingue H, Cliff J, Cumbana A, Bradbury JH (2008). Rising African cassava production, diseases due to high cyanide intake and control measures. J. Sci. Food Agric. 88:2043-49.

Nzwalo $\mathrm{H}$, Cliff $\mathrm{J}$ (2011). Konzo: from poverty, cassava and cyanogen intake to toxico-nutritional neurological disease. PloS Negl. Trop. Dis. 5(6): e1051.doi:10.1371/journal.pntd.0001051.

Projet Sphere : La charte humanitaire et les standards minimum de 
l'intervention humanitaire, page 258.

Unicef (2012). Unicef/Ministère de la Santé publique:Protocole national

de Prise en charge integrée de la malnutrition aiguë (PCIMA), Kinshasa, Avril 2012.

World Health Organisation (1996). Konzo: a distinct type of upper motor neuron disease. Wkly. Epidemiol. Rec. 71:225-232. 